\title{
PAPERS
}

\section{A prospective study of oesophageal function in patients with normal coronary angiograms and controls with angina}

\author{
R A Cooke, A Anggiansah, J B Chambers, W J Owen
}

\begin{abstract}
Aims-To compare the incidence of oesophageal abnormalities and their correlation with chest pain in patients with normal coronary angiograms, and in controls with angina.

Patients-Sixty one patients with normal coronary angiograms (NCA group) referred to a single cardiac centre between March 1990 and April 1991; 25 matched controls with confirmed coronary artery disease (CAD group).
\end{abstract}

Setting-Cardiac referral centre and oesophageal function testing laboratory.

Main outcome measures-Oesophageal manometry, provocation tests, and 24 hour ambulatory pH monitoring.

Results-Simultaneous contractions were more common $(6.7 \%$ versus $0.8 \%, p<0.01)$, and the duration of peristaltic contractions was longer ( 2.9 versus 2.4 seconds, $p<0.01$ ) in the NCA group than in the CAD group. There were no group differences in the amplitude of peristaltic contractions, and none had nutcracker oesophagus. Ten (16\%) patients with NCA and no patients with CAD had diffuse spasm $(p=0.03)$. Twenty one $(34 \%)$ patients with NCA, and five $(20 \%)$ patients with CAD had abnormal gastro-oesophageal reflux $(p>0.05)$. There was no significant difference between the groups in the number of patients whose pain was temporally related to $\mathrm{pH}$ events. Particular chest pain characteristics, or the presence of additional oesophageal symptoms, were not predictive of an oesophageal abnormality.

Conclusion-Oesophageal function tests commonly implicate the oesophagus as a source of pain in patients with normal coronary angiograms. With the exception of simultaneous contractions during manometry however, the incidence of abnormalities and in particular the correlation of pH events with chest pain are as common in patients with normal coronary angiograms as in controls with angina. The oesophagus may often be an unrecognised source of pain in both groups of patients. (Gut 1998;42:323-329)
Keywords: oesophageal function; coronary artery disease; chest pain

The oesophagus is commonly implicated in patients with chest pain and normal coronary angiograms. Previous studies using oesophageal function tests however, have recruited patients referred to the oesophageal laboratory, raising the possibility of selection bias. $^{1-3}$ Furthermore, there is little published data about the prevalence of oesophageal dysfunction in patients with angina. Svensson et al reported a similar incidence of oesophageal abnormalities. This study however used old technology and the robustness of the diagnosis of angina was in doubt on account of a high incidence of "atypical" symptoms. ${ }^{4}$ More recent reports have generally involved small, poorly defined groups and incomplete oesophageal investigations. ${ }^{5} 6$

The objective of the present prospective, observational study was to compare the incidence of oesophageal abnormalities, and their correlation with chest pain in patients with normal coronary angiograms, and in a small but representative group of controls with angina.

\section{Subjects}

Between March 1990 and April 1991, 1022 consecutive patients underwent coronary angiography as part of the investigation of chest pain. Of these, $84(8.2 \%)$ had completely normal angiograms and no evidence of spontaneous coronary spasm. Patients with mitral valve prolapse (three patients), left ventricular hypertrophy (four patients), or abnormalities of resting wall motion on echocardiography (five patients) were excluded. In addition, five patients were excluded because of previous myocardial infarction, and six declined entry to the study. There remained a study group of 61 patients (normal coronary artery (NCA) group). Table 1 lists their demographic data and symptom characteristics.

Twenty five sex matched controls with angina were recruited (coronary artery disease (CAD) group). All had "typical" symptoms and evidence of ischaemia during exercise treadmill testing as a requirement for entry. In
Accepted for publication 9 October 1997 
Table 1 Demographic data and symptoms in patients with normal coronary angiograms (NCA), controls (CAD), and 65 matched consecutive admissions with confirmed coronary artery disease (Parent CAD)

\begin{tabular}{llll}
\hline & $N C A(n=61)$ & $C A D(n=25)$ & Parent CAD (n=65) \\
\hline Age (mean (SD)) & $54(9)$ & $59(8)$ & $61(9)$ \\
Sex $(\mathrm{M} / \mathrm{F})$ & $23 / 38$ & $10 / 15$ & $24 / 41$ \\
Smokers & $12(20)$ & $5(20)$ & $23(35)$ \\
Cholesterol (mmol/1) (mean (SD)) & $6.0(1.5)$ & $7.0(1.1)$ & $0.8(1.5)$ \\
Diabetes & 0 & 0 & $28(43)$ \\
Hypertension & $20(33)$ & $11(44)$ & $8(12)$ \\
Abnormal rest ECG & $14(23)$ & $2(8)$ & $37 / 56(66)$ \\
Abnormal exercise ECG & $14(23)$ & $25(100)$ & $65(100)$ \\
Chest pain characteristics & $58(95)$ & $25(100)$ & $35(54)$ \\
Chest pain on exertion & $50(82)$ & $10(40)$ & $56(86)^{\star \star}$ \\
Chest pain at rest & $22(36)$ & $22(88)$ & $14(22)^{\star \star}$ \\
Usual duration $\leqslant 5$ min & $38(62)$ & $5(20)$ & $19(29)^{\star \star}$ \\
Predictability <10/10 & $40(66)$ & $4(16)$ & $36(55)$ \\
Rest pain $\geqslant 2 / 10$ & $40(66)$ & $12(48)$ & $20(31)$ \\
Radiation to arms & $17(28)$ & $7(28)$ & $12(19)$ \\
Radiation to back & $20(33)$ & $7(28)$ & $53(81)$ \\
Nocturnal & $32(52)$ & $18(72)$ & $8(13)$ \\
Frequency of pain & $23(38)$ & $6(24)$ & $4(6)$ \\
Daily & $6(10)$ & $1(4)$ & $25(38)$ \\
Weekly & $21(34)$ & $8(32)$ & $3(5)^{\star \star}$ \\
Occasional & $14(23)$ & 0 & $19(29)$ \\
Additional symptoms & $20(33)$ & $6(24)$ & $20(31)$ \\
Heartburn & $26(43)$ & $6(24)$ & $2(3)^{\star \star}$ \\
Dysphagia & $12(20)$ & 0 & \\
Waterbrash & & & \\
Flatulence & & & \\
Variable stool habit & & & \\
\hline
\end{tabular}

Results are expressed as $\mathrm{n}(\%)$ except where shown.

${ }^{\star \star} \mathrm{p}<0.01 v$ NCA group. There were no significant differences between CAD and Parent CAD groups.

addition, all had significant obstructive coronary disease defined as greater than $70 \%$ luminal diameter narrowing in at least one major epicardial artery and no previous myocardial infarction. They were compared with a sex matched parent population of 65 consecutive patients with significant obstructive coronary disease and no previous infarction. There were no significant differences in age, incidence of risk factors for coronary disease, chest pain characteristics, or incidence of oesophageal symptoms between the control CAD group and the parent population (table

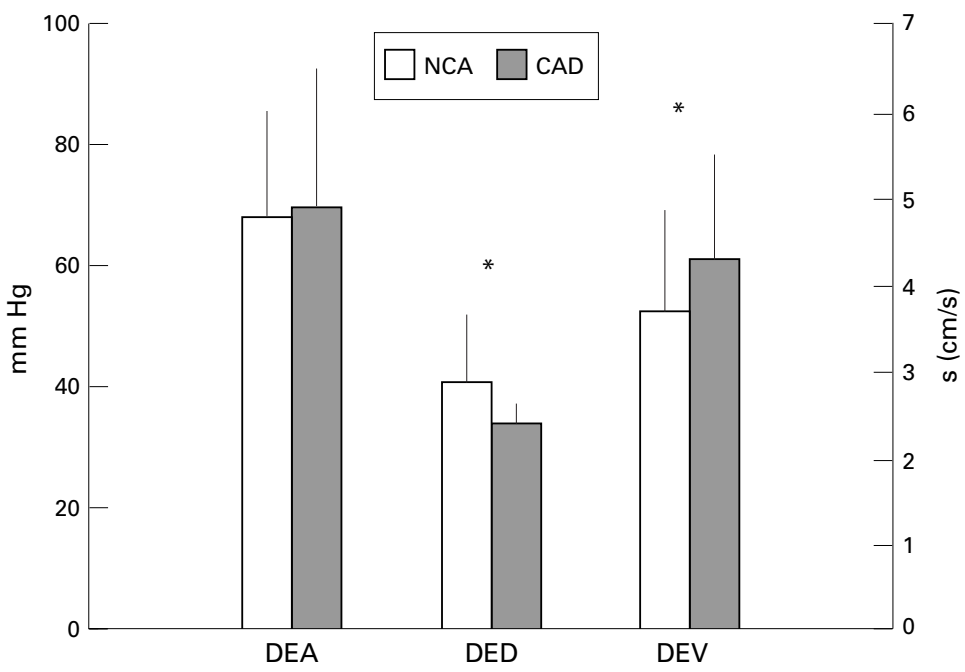

\begin{tabular}{llll}
\hline & NCA & CAD & p Value \\
\hline DEA $(\mathrm{mm} \mathrm{Hg})$ & $67.8(29.4)$ & $69.4(25.6)$ & 0.9 \\
DED $(\mathrm{s})$ & $2.9(0.7)$ & $2.4(0.4)$ & $<0.001 \dagger$ \\
DEV $(\mathrm{cm} / \mathrm{s})$ & $4.3(1.2)$ & $4.3(1.2)$ & $0.037 \ddagger$ \\
\hline
\end{tabular}

Data are expressed as mean (SD).

†95\% Confidence interval (CI) 0.2 to $0.7 ; \ddagger 95 \%$ CI 0.04 to 1.2 .

Figure 1 Comparison of distal peristaltic amplitude (DEA), duration (DED), and velocity (DEV) in NCA and CAD groups. ${ }^{\star} p<0.5$.
1). All controls had chronic stable angina. None had left main stem stenoses, three vessel disease, or critical stenoses of the proximal left anterior descending artery.

None of the patients or controls had previously been investigated by a gastroenterologist or had prominent symptoms of gastrooesophageal reflux disease. All medication likely to interfere with oesophageal motility or affect the incidence of gastro-oesophageal reflux with the exception of short acting nitrates was discontinued for 48 hours before testing. Written, informed consent was obtained, and the study had the approval of the hospital's ethics committee.

\section{Methods}

PATIENT CHARACTERISTICS

Patient demographic and symptom characteristics were recorded using standard questionnaires. For the purposes of the study chest pain was considered "typical" where it occurred on exercise and satisfied at least two of the following criteria: reproducibly provoked by exercise; rest pain accounting for no more than $10 \%$ of pain episodes; or duration of pain of five minutes or less. Pain which occurred at rest, or which satisfied none or only one of the above criteria was considered to be "atypical".

MANOMETRY

Baseline manometry was performed after a four hour fast with the patient sitting upright. A pressure catheter (2.5 mm external diameter) (Gaeltec Ltd, Scotland, UK) consisting of six surface mounted microtransducers arranged at $5 \mathrm{~cm}$ intervals was passed transnasally into the stomach. After a five minute resting period, the lower oesophageal sphincter was located using the station pull through technique, and a minimum of 10 wet swallows ( $5 \mathrm{ml}$ bolus) recorded in the oesophageal body. The electrocardio- 
Table 2 Incidence of oesophageal abnormalities in NCA and CAD groups

\begin{tabular}{lll}
\hline & $N C A(n=61)$ & $C A D(n=25)$ \\
\hline Manometric abnormalities & $10(16 \%)$ & $0 \star$ \\
$\quad$ Diffuse spasm & 0 & 0 \\
$\quad$ Nutcracker & 0 & 0 \\
Achalasia & $2(4 \%)$ & $1(4 \%)$ \\
$\quad$ Non-specific & $20(33 \%)$ & $5(20 \%)$ \\
Provocation testing & 0 & $\mathrm{NA}$ \\
$\quad$ Acid perfusion & $21(34 \%)$ & $5(20 \%)$ \\
$\quad$ Edrophonium & $14(23 \%)$ & $6(24 \%)$ \\
Ambulatory pH monitoring & & \\
$\quad$ Abnormal reflux & & \\
SI $\geqslant 25 \%$ & &
\end{tabular}

gram was monitored throughout using a two channel recorder (Siemens, Stockholm, Sweden).

The pressure recordings were stored on disk for off line analysis using an IBM compatible computer and commercially available software (Aspen Medical GR 800). Interpretation was by two experienced observers who were unaware of the clinical details or the results of the other tests. Standard definitions of dysmotility were used. ${ }^{7}$

\section{PROVOCATION TESTING}

The acid perfusion test was performed by first instilling normal saline into the oesophageal body at a rate of $10 \mathrm{ml}$ per minute (or less if this rate was not tolerated), and then switching to $0.1 \mathrm{M}$ hydrochloric acid. The acid infusion was stopped after a maximum of $100 \mathrm{ml}$ or sooner if chest pain developed. A test was defined as positive if the patient's usual chest pain was reproduced by acid but not saline.

The edrophonium test was performed only in patients in whom there were no contraindi-

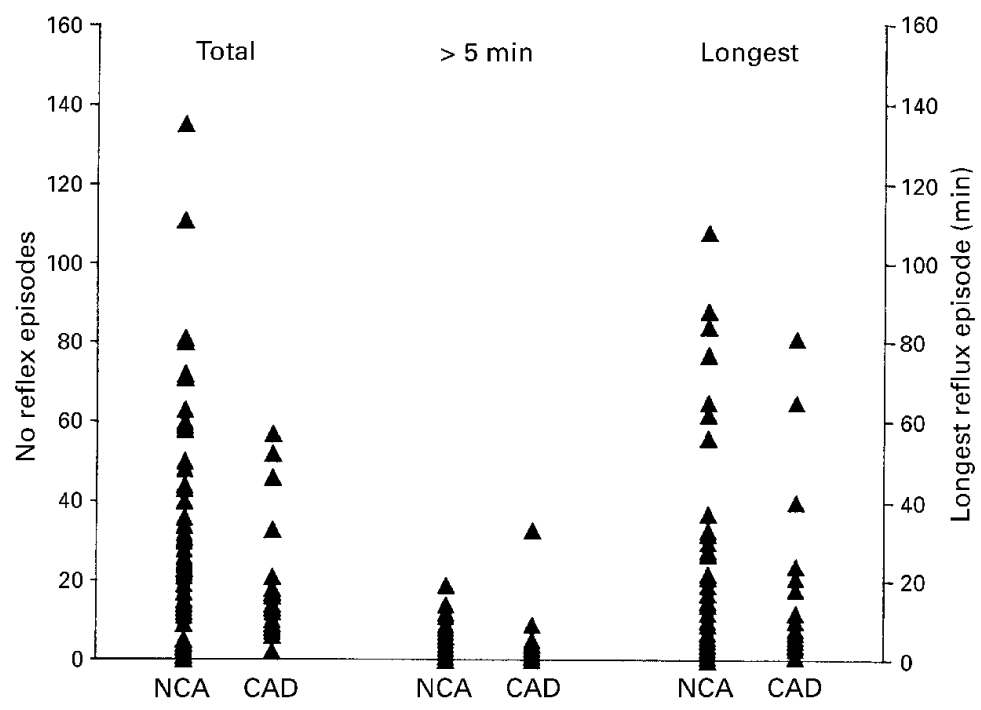

\begin{tabular}{llll}
\hline Reflux episodes & NCA & CAD & p Value \\
\hline Total number & $20(3.2$ to 39.0$)$ & $12.0(7.5$ to 17.5$)$ & 0.3 \\
Number $>5$ min & $1.0(0.0$ to 5.0$)$ & $1.0(0.0$ to 3.0$)$ & 0.9 \\
Longest duration & $9.0(1.2$ to 21.7$)$ & $7.0(5.0$ to 15.0$)$ & 0.7
\end{tabular}

Data are expressed as median (interquartile range).

${ }^{\star}$ Mann-Whitney U test.

Figure 2 Comparison of parameters of gastro-oesophageal reflux during ambulatory $p H$ monitoring: percentage reflux episodes. cations. It was not performed in controls (CAD group) since this was not considered ethical. Normal saline placebo $(10 \mathrm{ml})$ was injected intravenously followed by $10 \mathrm{mg}$ edrophonium hydrochloride provided that no symptoms were reported. As with the acid perfusion test, a positive edrophonium test was defined by the reproduction of the patient's usual chest pain. In addition, however, the occurrence of a new motility disorder was required for a test to be positive. $^{8}$

\section{TWENTY FOUR HOUR AMBULATORY $\mathrm{pH}$}

MONITORING

Twenty four hour ambulatory $\mathrm{pH}$ monitoring was performed using a probe (external diameter $2.1 \mathrm{~mm}$ ) with a distal antimony monocrystalline $\mathrm{pH}$ sensor and external cutaneous reference electrode. The sensor was positioned $5 \mathrm{~cm}$ cephalad to the upper margin of the manometrically defined lower oesophageal sphincter. Changes in distal oesophageal $\mathrm{pH}$ were recorded on a "Digitrapper" (Synectics Medical, Sweden) which was strapped to the patient's waist. The system was calibrated at $\mathrm{pH} 1.0$ and 7.0 (Synectics buffer solution) before insertion and after each study. Gastric acidity was confirmed in all patients by passing the probe into the stomach before its final placement above the lower oesophageal sphincter. The probe was secured by tape to the nostril. A diary card and an event marker button were used to record the time of onset of symptoms during the 24 hour ambulatory period. Alcohol, and food or beverages with $\mathrm{pH}$ values less than 5 were avoided, but otherwise the subjects were unrestricted.

On completion, data were transferred from the Digitrapper to an IBM compatible personal computer for graphical display and numerical analyses using commercially available software (Esophagram Version 5.5, Gastrosoft Inc.). All recordings were checked visually for technical quality to exclude artefact. A reflux episode was defined as any fall in distal gastrooesophageal $\mathrm{pH}$ below a threshold of $4 \mathrm{pH}$ units for more than 10 seconds. Abnormal reflux was defined by the oesophageal $\mathrm{pH}$ falling below $4 \mathrm{pH}$ units for more than $5.5 \%$ of the 24 hour period. ${ }^{9}$ A symptom index was expressed for symptoms occurring spontaneously during the 24 hour period. This was calculated by dividing the number of pain episodes which were temporally related to gastro-oesophageal reflux by the total number of pain episodes. ${ }^{10} \mathrm{~A}$ temporal relationship was defined by chest pain beginning within two minutes before and two minutes after a reflux episode. A symptom index of at least $25 \%$ was used to define symptomatic reflux. ${ }^{11}$

\section{STATISTICS}

The data were described as either the mean (SD) or median (interquartile range), and group comparisons were made by Student's $t$ test or the Mann-Whitney U test depending on the distribution of the variables. The $\chi^{2}$ test with Yates's correction, or the Fisher exact test were used for discrete variables. A $p$ value of 


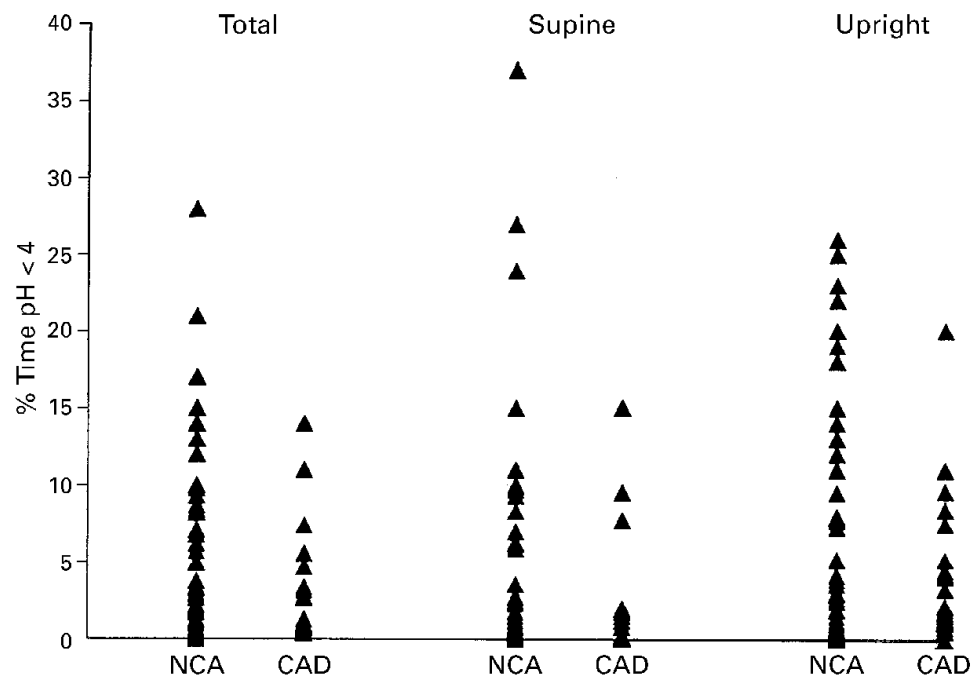

\begin{tabular}{llll}
\hline Per cent time $p H<4$ & NCA & CAD & p Value \\
\hline Total $(24 \mathrm{~h})$ & $1.9(0.3$ to 8.6$)$ & $1.3(0.7$ to 4.1$)$ & 0.90 \\
Supine & $0.5(0.0$ to 5.3$)$ & $0.0(0.0$ to 1.4$)$ & 0.09 \\
Upright & $2.3(0.4$ to 10.3$)$ & $1.8(1.1$ to 4.9$)$ & 0.98 \\
\hline
\end{tabular}

Data are expressed as median (interquartile range).

${ }^{\star}$ Mann-Whitney U test.

Figure 3 Comparison of parameters of gastro-oesophagel reflux during ambulatory $p H$ monitoring: reflux episodes.

less than 0.05 was considered to be statistically significant.

\section{Results}

PATIENT CHARACTERISTICS

Fifty eight $(95 \%)$ patients with NCA, and all patients with CAD had a history of exertional chest pain. There were however, significant differences between the groups in the reproducibility of pain with exercise, the duration of pain, and the frequency of rest pain (table 1$)$. Thirty three (54\%) patients with NCA, and nine (36\%) patients with CAD had additional oesophageal symptoms (table 1). The incidence of heartburn and waterbrash were similar, but intermittent dysphagia was more common in NCA (14 (23\%) patients), than in patients with CAD (no patients) $(\mathrm{p}<0.01)$. Twelve $(20 \%)$ patients with NCA, and no patients with CAD had variable stool habit $(\mathrm{p}=0.015)$.

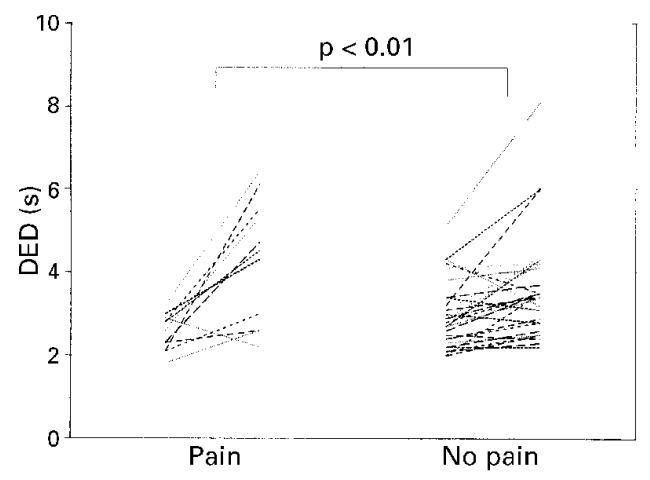

Figure 4 Mean distal peristaltic duration (DED) at baseline and after edrophonium in patients who reported pain, compared with patients who did not report pain.
MANOMETRY

Simultaneous contractions accounted for $6.7 \%$ of the total number of contractions in the NCA group, but only $0.8 \%$ in the CAD group $(p<0.01)$. There were no significant differences between the groups in the mean distal amplitude of peristaltic contractions, though the mean distal duration of peristaltic contractions was significantly longer, and the mean distal velocities significantly shorter in the NCA group, compared with the CAD group (fig 1).

Ten (16\%) patients with NCA, and no patients with CAD had diffuse spasm $(p=0.03)$ (table 2). All had normal or low amplitude and duration contractions and none had chest pain at the time of manometry. Overall, $12(20 \%)$ patients with NCA, and one (4\%) patient with CAD had abnormal oesophageal manometry ( $>>0.05)$ (table 2).

TWENTY FOUR HOUR AMBULATORY OESOPHAGEAL pH MONITORING

Gastro-oesophageal reflux was more common in the NCA group compared with the CAD group, but there were no significant differences between the groups in the distribution of any of the measured parameters of gastrooesophageal reflux (figs 2 and 3). Twenty one (34\%) patients with NCA and five (20\%) patients with CAD had abnormal gastrooesophageal reflux $(\mathrm{p}>0.05)$ (table 2$)$.

Thirty five $(57 \%)$ patients with NCA had chest pain during ambulatory $\mathrm{pH}$ monitoring. Thirteen $(37 \%)$ of these had abnormal gastrooesophageal reflux, of whom $10(77 \%)$ had pain which was temporally related to episodes of reflux. A further four patients had pain which was temporally related though their reflux parameters were normal. For those patients whose pain was temporally related to episodes of reflux their mean number of symptoms per patient was 3.4 (SD 2.4); their mean symptom index score was $68 \%$ (SD $31 \%$, median $59 \%$, and interquartile range $37 \%$ to $100 \%)$.

In the CAD group, $13(52 \%)$ patients reported chest pain during ambulatory $\mathrm{pH}$ monitoring. In six $(46 \%)$ of these their pain was temporally related to episodes of gastrooesophageal reflux. The mean number of chest pain episodes per patient was 2.3 (SD 1.0); their mean symptom index score was $64 \%$ (SD $29 \%$, median $50 \%$, and interquartile range $46 \%$ to $100 \%$ ) ( $p>0.05$ versus NCA group).

\section{PROVOCATION TESTS}

Overall, the acid perfusion test and/or a temporal correlation of symptoms with episodes of gastro-oesophageal reflux during ambulatory $\mathrm{pH}$ monitoring identified the oesophagus as a probable source of chest pain in $27(44 \%)$ patients with NCA, and in nine $(36 \%)$ patients with CAD ( $p>0.05)$.

The acid perfusion test was positive in 20 (33\%) patients with NCA, and also in five $(20 \%)$ patients with CAD ( $p>0.05)$. None of the patients in either group had simultaneous electrocardiographic abnormalities. The maximum increase in heart rate was nine beats per 
Table 3 Clinical correlates

\begin{tabular}{|c|c|c|c|c|c|}
\hline & $\begin{array}{l}\text { Patients } \\
(n=61)\end{array}$ & $\begin{array}{l}P T(+) \\
(n=26)\end{array}$ & Motility $(n=12)$ & $G O R(n=21)$ & $S R(n=14)$ \\
\hline \multicolumn{6}{|c|}{ Chest pain characteristics } \\
\hline Duration $\leqslant 5 \mathrm{~min}$ & 36 & 31 & 33 & 57 & 57 \\
\hline Predictability $10 / 10$ & 38 & 35 & 50 & 38 & 50 \\
\hline Rest pain $\leqslant 2 / 10$ & 34 & 35 & 33 & 48 & 57 \\
\hline Typical pain & 28 & 31 & 33 & 43 & 57 \\
\hline \multicolumn{6}{|l|}{ Symptoms of GORD } \\
\hline Heartburn & 34 & 35 & 33 & 33 & 43 \\
\hline Dysphagia & 23 & 31 & 8 & 24 & 36 \\
\hline Waterbrash & 33 & 38 & 33 & 38 & 43 \\
\hline Any of the above & 54 & 54 & 50 & 52 & 64 \\
\hline Abnormal ECG & 23 & 19 & 17 & 24 & 14 \\
\hline
\end{tabular}

Results are expressed as percentages.

PT (+), provocation test positive; GOR, abnormal gastro-oesophageal reflux during ambulatory pH monitoring; SR, symptomatic reflux during ambulatory $\mathrm{pH}$ monitoring.

minute, and in most patients there was no significant change in heart rate.

The edrophonium test was performed in the NCA group only. It reproduced their pain in $13 / 50(26 \%)$ patients, but in none was this associated with the production of a new motility disorder. In three patients manometry was abnormal at baseline. Figure 4 shows that the duration of peristaltic contractions in the distal oesophageal body increased significantly more in patients who reported pain compared with those who did not report pain. Seven of the 13 (54\%) patients with pain during the edrophonium test also had their pain reproduced by acid perfusion testing, and four $(31 \%)$ had pain which was temporally related to acid reflux during ambulatory $\mathrm{pH}$ monitoring.

\section{CLINICAL CORRELATES}

In the NCA group the proportion of patients with "typical" pain was higher in patients whose pain was temporally related to $\mathrm{pH}$ events during ambulatory monitoring than in the group as a whole. There were no chest pain characteristics, however, which were strongly predictive of an oesophageal abnormality (table 3). Similarly, the incidence of oesophageal abnormalities was as high in patients with additional oesophageal symptoms as in those with no symptoms (table 3 ).

In the CAD group four of nine $(44 \%)$ patients with, compared with four of $16(25 \%)$ with no additional oesophageal symptoms had abnormal gastro-oesophageal reflux or pain which was temporally related to $\mathrm{pH}$ events during ambulatory $\mathrm{pH}$ monitoring. Oesophageal symptoms were present in four of five $(80 \%)$ patients with positive, compared with five of $20(25 \%)$ patients with negative acid perfusion tests. Only one patient in this group had abnormal manometry (non-specific). They did not report oesophageal symptoms.

\section{Discussion}

In this prospective observational study there was a high incidence of oesophageal abnormalities in patients with normal coronary angiograms. With the exception of simultaneous contractions during manometry, however, the incidence of abnormalities was not significantly different to that in controls with confirmed angina.

A diagnosis of diffuse spasm was made in almost a fifth of patients with NCA, and in no controls. Only one of these had a history of intermittent dysphagia consistent with impaired oesophageal transit. The incidence of simultaneous contractions in the control group was low, and similar to that reported in healthy volunteers by Richter et al. ${ }^{7}$ The observation confirms the importance of oesophageal spasm as a potential cause of chest pain in patients with normal coronary angiograms.

Despite previous reports of an association of high amplitude peristalsis with non-cardiac chest pain there were no differences between the groups in peristaltic amplitude, and none had nutcracker oesophagus. ${ }^{12}$ Differences in catheter sizes and recording assemblies may explain the relatively low peristaltic amplitudes in our study (mean (2 SD) less than $130 \mathrm{~mm}$ $\mathrm{Hg}$ ) compared with Richter et al (mean (2 SD) greater than $180 \mathrm{~mm} \mathrm{Hg}$ ). The Gaeltec catheter (2.5 $\mathrm{mm}$ diameter) used in our laboratory is $2 \mathrm{~mm}$ smaller than that used by Richter et al $(4.5 \mathrm{~mm}){ }^{7}$ The distribution of peristaltic amplitudes in our study is in close agreement with that reported by Wilson et al for a normal population, using a similar Gaeltec pressure monitoring system. ${ }^{13}$

PREVIOUS STUDIES

The observation that the oesophagus may produce pain which may resemble, or even provoke angina is not recent. ${ }^{14}{ }^{15}$ In a prospective study Schofield et al reported abnormal gastro-oesophageal reflux during ambulatory $\mathrm{pH}$ monitoring in $11 / 51(21 \%)$ patients with normal coronary angiograms, and induced gastro-oesophageal reflux which coincided with the onset of chest pain during treadmill testing in a further $13(23 \%) .{ }^{16}$ The observation in the present study of a high incidence of gastro-oesophageal reflux and its coincidence with chest pain in the majority of cases is in agreement with this study, but unlike their study we included both patients with "typical" and "atypical" symptoms. In a more recent study Nevens et al reported abnormal gastrooesophageal reflux in $15 / 37(47 \%)$ patients, and a motility disorder in a further $11(30 \%){ }^{17}$ As in the study of Schofield et al they studied only patients with "typical" pain. Only eight patients had symptoms during ambulatory monitoring though in six of these pain was considered to be related to an oesophageal event. 
The observation that the incidence of oesophageal abnormalties was as high in patients with "typical", as in patients with "atypical" pain is important. The incidence of abnormalities moreover was high even where there were no additional oesophageal symptoms. Thus all patients with unexplained chest pain following coronary angiography should be considered for oesophageal testing.

The importance of the prospective design of the present study is illustrated by the study of Hewson et al in which "nutcracker" oesophagus was reported in $29 \%$ of 45 patients referred to the oesophageal laboratory. ${ }^{18}$ The study was repeated prospectively in a sample of 100 patients and the incidence was only $6 \% .{ }^{11}$ One might expect high amplitude contractions in anxious patients selected for oesophageal investigations either because of refractory symptoms or a failure of negative cardiac investigations to reassure..$^{19}$ Since our patients were unselected this might explain the relatively low incidence of "nutcracker" oesophagus. It is possible however that the incidence of "nutcracker" oesophagus has been overestimated in the past due to the use of normal values based on studies using poorly compliant manometry systems. ${ }^{21}$

A high incidence of oesophageal abnormalities has previously been reported in patients with coronary heart disease, and with suspected non-cardiac chest pain. ${ }^{22}{ }^{23}$ Few studies have described the incidence of oesophageal abnormalities in patients with confirmed angina. DeCaestecker et al reported abnormal motility in three of $10(30 \%)$ patients, though the high incidence of dysmotility in their study may have been due to a failure to withdraw $\beta$ blockers. ${ }^{6}$ Schofield et al, in a study of 20 patients, and in agreement with our study, reported a significantly lower incidence of abnormal motility. ${ }^{5}$

Since each of our controls had "typical" chest pain, significant ST depression during treadmill stress testing, and angiographically confirmed obstructive coronary heart disease, there is little doubt that their chest pain was cardiac. One explanation of the association of pain with $\mathrm{pH}$ events in this group might be an inability of patients with angina to differentiate ischaemic cardiac chest pain from oesophageal pain. ${ }^{14}$ The association may however be explained by "linkage" or the so called "viscerocardiac reflex". Thus Alban Davies et al reported a reduced exercise threshold and earlier onset of ischaemia compared with placebo after acid infusion of the distal oesophagus. ${ }^{24}$ Mellow et al provoked chest pain which was indistinguishable from their usual angina during acid perfusion testing in 10 of 25 (40\%) patients. ${ }^{25}$ In three of the 10 patients it is likely that angina was provoked by the stress of oesophageal intubation, but in the remaining patients, as in the present study, there were no significant changes in the heart rate/blood pressure products.

None of our patients developed significant motor disturbances with edrophonium though the peristaltic duration increased significantly more in patients who reported pain compared with those who did not report pain. This is in agreement with previous observations. ${ }^{26}$ In seven of $13(54 \%)$ patients whose pain was reproduced by edrophonium it was also reproduced by acid perfusion. In addition, four (31\%) patients with pain provoked by edrophonium had acid related pain during ambulatory $\mathrm{pH}$ monitoring. The poor specificity of edrophonium has been noted. ${ }^{27}$ The observations support the concept of polymodal pain receptors in the distal oesophagus, but may also be explained by increased somatic awareness. ${ }^{28}$

\section{LIMITATIONS}

There are a number of limitations to the study. The sample of controls with confirmed angina is small, though it represents one of the largest series reported to date. It is our experience, and that of others, that such patients often decline oesophageal testing. ${ }^{5}$ No differences in age, sex, smoking habits, chest pain characteristics, or oesophageal symptoms were noted between our sample and a larger group of patients with confirmed coronary artery disease. We therefore consider it reasonable to conclude that the sample was representative. The withdrawal of medication for 48 hours before testing was considered reasonable but it is accepted that in the case of $\beta$ blockers a longer period of withdrawal may have been required for complete washout of the drug.

\section{CONCLUSIONS}

In conclusion, oesophageal function tests are useful and commonly implicate the oesophagus as a source of chest pain in patients with angiographically normal coronary arteries. With the exception of a lower incidence of simultaneous contractions during manometry, however, the incidence of abnormalities and in particular the correlation of $\mathrm{pH}$ events with chest pain are as common in patients with normal coronary angiograms as in controls with confirmed angina. The oesophagus may be a commonly unrecognised source of pain not only in patients with negative cardiac investigations but also in patients with angina. Cimochowski GE, O'Drobinak JO. Oesophageal function in patients with angina type chest pain and normal coronary angiograms. Ann Surg 1982;196:488-98.

2 DeCaestecker JS, Brown J, Blackwell JN, Heading RC. The oesophagus as a cause of recurrent chest pain: which patients should be investigated and which test should be patients should be investigat 1985 ;ii: 1143-6.

3 Hick DG, Morrison JFB, Casey JF, Al-Ashhab W, Williams GJ, Davies GA. Oesophageal motility, luminal pH, and electrocardiographic-ST segment analysis during spontaneous episodes of angina like chest pain. Gut 1991;33:7986

4 Svensson O, Stenport G, Tibbling L, Wranne B. Oesophageal function and coronary angiogram in patients with disabling chest pain. Acta Med Scand 1978;204:173-8.

5 Schofield PM, Whorwell PJ, Brooks NH, Bennett DH, Jones PE. Oesophageal function in patients with angina pectoris: a comparison of patients with normal coronary angiograms and patients with coronary artery disease. Digestion 1989;42:70-8.

6 DeCaestecker JS, Pryde A, Heading RC. Oesophageal abnormalities in patients with symptomatic coronary artery disease [abstract]. Gullet 1992;2:74-6.

7 Richter JE, Wu WC, Johns DN, et al. Oesophageal manometry in 95 healthy adult volunteers. Variability of pressures etry in 95 healthy adult volunteers. Variability of pressures
with age and frequency of abnormal contractions. Dig Dis With age and frequency

8 Linsell J, Owen WJ, Mason RC, Anggianshah A. Edrophonium provocation test in the diagnosis of diffuse oesophageal spasm. Br F Surg 1987;74:688-9. 
9 Richter JE, Bradley LA, DeMeester TR, Wu WC. Normal 24 hour ambulatory oeosphageal $\mathrm{pH}$ values. Influence of 24 hour ambulatory oeosphageal $\mathrm{pH}$ values. Influence of
study centre, $\mathrm{pH}$ electrode, age, and gender. Dig Dis Sci study centre, $\mathrm{pH}$

10 Weiner GJ, Richter JE, Copper JB, Wu WC, Castell DO. The symptom index: a clinically important parameter of ambulatory 24 hour oesophageal $\mathrm{pH}$ monitoring. $\mathrm{Am} \mathcal{F}$ Gastroenterol 1988;83:358-61.

11 Hewson EG, Sinclair JW, Dalton CB, Richter JE. Twenty four hour oesophageal $\mathrm{pH}$ monitoring: the most useful tes for evaluating non cardiac chest pain. $A m \mathcal{F} \mathrm{Med}$ 1991;90:576-83.

12 Benjamin SB, Gerhardt DC, Castell DO. High amplitude peristaltic oesophageal contractions associated with chest pain and/or dysphagia. Gastroenterology 1979;77:473-83.

13 Wilson JA, Pryde A, Macintyre CCA, Heading RC. Normal pharyngooesophageal motility. A study of 50 healthy pharyngooesophageal motility. A

14 Kramer P, Hollander W. Comparison of experimental oesophageal pain with clinical pain of angina pectoris and oesophageal pain with clinical pain of angina pect

15 Bennett JR, Atkinson M. The differentiation between oesophageal and cardiac pain. Lancet 1966;ii: 1123-7.

16 Schofield PM, Bennett DH, Whorwell PJ, et al. Exertional gastro-oesophageal reflux: a mechanism for symptoms in patients with angina pectoris and normal coronary angiograms. $B M \mathcal{F}$ 1987;294:1459-61.

17 Nevens F, Janssens J, Piessens J, Ghillebert G, DeGeest H, Vantrappen G. Prospective study on prevalence of oesophageal chest pain in patients referred on an elective basis to a cardiac unit for suspected myocardial ischaemia. Dig Dis Sci 1991;36:229-35.

18 Hewson EG, Dalton CB, Richter JE. Comparison of oesophageal manometry, provocative testing, and ambulatory monitoring in patients with unexplained chest pain. Dig Dis Sci 1990;35:302-9.
19 Anderson KO, Dalton CB, Bradley LA, Richter JE. Stress induces alteration of oesophageal pressures in healthy volunteers and non cardiac chest pain patients. Dig Dis Sci 1989;34:83-91.

20 Young LD, Richter JE, Anderson KO, et al. The effects of psychological and environmental stressors on peristaltic oesophageal contractions in healthy volunteers. Psychophysiology 1987;24:133-41.

21 Dalton CB, Castell DO, Hewson EG, Wu WC, Richter JE. Diffuse oesophageal spasm. A rare motility disorder not characterised by high amplitude contractions. Dig Dis Sci 1991;36:1025-8.

22 Garcia-Pulido J, Patel PH, Hunter WC, Douglas JE, Thomas E. Oesophageal contribution to chest pain in patients with coronary artery disease. Chest 1990;98:80610 .

23 Singh S, Richter JE, Hewson EG, Sinclair JW, Hackshaw BT. The contribution of gastroesophageal reflux to chest pain in patients with coronary artery disease. Ann Intern Med 1992;117:824-30.

24 Alban Davies H, Page Z, Rush EM. Oesophageal stimulation lowers external angina threshold. Lancet 1985;ii:1011.

25 Mellow MH, Simpson AG, Watt L, Schoolmeester L, Haye OL. Oesophageal acid perfusion in coronary artery disease OL. Oesophageal acid perfusion in coronary

26 Dalton CB, Hewson EG, Castell DO, Richter JE. Edrophonium provocation test in non cardiac chest pain. Evaluation of testing techniques. Dig Dis Sci 1990;35:1445-51.

27 DeCaestecker JS, Pryde A, Heading RC. Comparison of intravenous edrophonium and oesophageal acid perfusion during oesophageal manometry in patients with non cardiac chest pain. Gut 1988;29:1029-34.

28 Vantrappen G, Janssens G, Ghillebert G. The irritable oesophagus - a frequent cause of angina like pain. Lancet $1987 ; \mathrm{i}: 1232$. 